\title{
Assessing environmental quality: a novel approach
}

\author{
M. A. Pardal ${ }^{1, *}$, P. G. Cardoso ${ }^{1}$, J. P. Sousa ${ }^{2}$, J. C. Marques $^{1}$, D. Raffaelli ${ }^{3}$ \\ ${ }^{1}$ IMAR (Institute of Marine Research), and ${ }^{2}$ IAV (Institute of Environment and Life Sciences), Department of Zoology, \\ University of Coimbra, 3004-517 Coimbra, Portugal \\ ${ }^{3}$ Environment Department, University of York, Heslington, York YO10 5DD, UK
}

\begin{abstract}
A new approach to assess environmental integrity based on PRC analysis was proposed, tested, validated and developed. Environmental health assessment and community studies usually result in complex biological data sets. In order to find ecologically relevant patterns and tendencies from such sets of data it is necessary to reduce all the information to a summarised and simplified form, which might be more easily interpreted by ecologists, politicians, end-users and the population in general. However, several multivariate ordination methods currently used (e.g. redundancy analysis, principal component analysis, or multi-dimensional scaling) produce complex diagrams for the non-ecologist, which do not allow changes in biological communities over time to be easily understood. Here, we propose a recently developed method, principal response curves (PRC) analysis, to overcome these issues. This method has advantages over traditional ordination techniques, or any biotic index, in that it provides a powerful statistical analysis of temporal data series along spatial gradients. The PRC technique can make use of non-disturbed or unpolluted areas as reference sites with which other areas are compared, making it possible to assess changes in species composition between different areas over time. Moreover, individual species responses to stress agents can be inferred from the PRC curves. As well as providing insights into the behaviour of natural ecosystems - in particular, how ecosystem integrity changes over time - this new approach can potentially provide a practical tool for monitoring and implementing environmental policy instruments.
\end{abstract}

KEY WORDS: Environmental integrity $\cdot$ Environmental health $\cdot$ PRC analysis $\cdot$ Community studies

\section{INTRODUCTION}

In the face of global change, declines in environmental quality are of increasing concern, especially in densely populated areas. Assessing the well-being of ecological systems and instituting mitigation measures has become a priority. However, many of the tools and instruments presently available lack the rigour required for both the unambiguous detection of ecological impacts and the presentation of those impacts in an easily communicable way to policymakers, managers and stakeholders who are usually not biologists. For instance, within the European Union, the implementation of the Habitats Directive, the Water Framework Directive and Integrated Coastal Zone Management has prompted the search for novel biological indicators (Borja \& Perez 2000, Simboura \& Zenetos 2002, Borja et al. 2003) for the assessment of environmental quality, because traditional approaches are unable to capture entirely the natural variability of ecosystems. The most successful tools to date have been biological indices, which reduce the dimensionality of complex ecological data sets to a single univariate statistic, and ordination methods, which preserve more information in the data set by summarising its multi-dimensionality in a 2-D or 3-D plot within which ecological meaningful trends and patterns can be seen. However, the summary ordination plots and diagrams from traditional ordination methods (e.g. redundancy analysis: RDA; principal component analysis: $\mathrm{PCA}_{i}$ or multi-dimensional scaling: MDS) can still remain illusive and obscure to non-specialists and hence are difficult to interpret (Warwick \& Clarke 1991). This is especially true when a time factor is present within the data, because temporal trajectories are often non-linear in such plots. 
One approach to deal with the complexity of timedependency is the application of a recently developed method, principal response curves (PRC) (Van den Brink \& Ter Braak 1999). PRC analysis was originally conceived for aquatic ecotoxicology, but potentially it has much wider applications. PRC has advantages over traditional ordination techniques, in that it permits a formal and powerful statistical analysis of temporal (long-term) data series from spatial gradients. PRC analysis uses selected areas as reference sites and other areas (treated or impacted areas) are compared to these reference sites, allowing changes in the environmental quality to be assessed over time. By providing a yardstick or natural, undisturbed reference against which departures of other data can be seen, the approach is analogous to the log-normal plots described by Gray (1979) and the ordination/metaanalysis approach developed by Warwick \& Clarke (1993). PRC analysis has the additional advantage of providing an interpretation of impacts and change at the species level, because individual species responses to stress agents can be inferred from the PRC curves.

One of the most common environmental problems is the increase of organic pollution in coastal waters that usually leads to a shift in primary producers (e.g. an increase in green macroalgae). In common with many other estuaries, the Mondego, Portugal, has undergone significant eutrophication due to organic enrichment (Marques et al. 1993, 1997, Flindt et al. 1997,
Lillebø et al. 1999, Lopes et al. 2000, Pardal et al. 2000, Martins et al. 2001, Cardoso et al. 2002). As a response to the increase of nutrient (phosphorus and nitrogen) concentrations, macroalgal blooms have increased substantially, leading to the decline of seagrass Zostera noltii meadows (Martins et al. 2001, Cardoso et al. 2002), accompanied by structural changes in macrobenthic communities. Despite interannual variations over the last $20 \mathrm{yr}$, a consistent effect has been the decrease in species diversity and secondary production from the less stressed areas to the ones exhibiting stronger symptoms of eutrophication (Marques et al. 1997, Dolbeth et al. 2003, Cardoso et al. 2004). In 1998, a degree of management was attempted in the estuary which involved protecting the small patch of the seagrass bed, decreasing the nutrient loading to the system and increasing water transparency and velocities leading, at the present time, to the slow recovery of Zostera beds (Fig. 1). In the present paper, we explore and validate the use of PRC analysis in ecosystem health assessment using this well-documented system.

\section{MATERIALS AND METHODS}

The Mondego estuary, located on the western coast of Portugal, is a typical temperate small intertidal estuary. As with many other regions, this estuary shows symptoms of eutrophication which have resulted in an impoverishment of its environmental quality (Marques et al. 1993, 1997, Flindt et al. 1997, Lillebø et al. 1999, Pardal et al. 2000, Martins et al. 2001, Cardoso et al. 2002, Dolbeth et al. 2003). Three distinct areas within the estuary can be recognised along a spatial gradient of eutrophication: (1) Seagrass Zostera noltii beds, corresponding to the least eutrophic area (undisturbed/reference), are located downstream. This area is characterised by higher salinity values (20 to $30 \mathrm{~g} \mathrm{l}^{-1}$ ), lower total inorganic nitrogen (TIN) concentrations (15 to $30 \mu \mathrm{mol} \mathrm{N} \mathrm{l}^{-1}$ ) and higher water flows (1.2 to $1.4 \mathrm{~m} \mathrm{~s}^{-1}$ ). The mean organic matter content is $6.8 \pm 0.99 \%( \pm \mathrm{SD})$. (2) An intermediate eutrophic area is located in the middle section of the estuary corresponding to an area that supported seagrass beds 5 yr ago but not now, although rhizomes are still present in the sediment. The physical-chemical conditions are similar to those of the previous area. (3) The most eutrophic area is located in the upper reaches of the estuary, from where seagrasses disappeared without trace more than 15 yr ago, and where seasonal blooms of

green macroalgae Enteromorpha spp. now
Fig. 1. Location of the sampling areas in the south arm of the Mondego estuary. Area covered by Zostera noltii in 1986, 1993, 1997 and 2000 
regularly occur (Marques et al. 1993, 1997, Flindt et al. 1997, Lillebø et al. 1999, Pardal et al. 2000, Martins et al. 2001, Cardoso et al. 2002). This area is characterised by lower salinity values (15 to $25 \mathrm{~g} \mathrm{l}^{-1}$ ), higher TIN concentrations (30 to $50 \mu \mathrm{mol} \mathrm{N} \mathrm{l}^{-1}$ ) and lower water flows ( 0.8 to $\left.1.2 \mathrm{~m} \mathrm{~s}^{-1}\right)$. The mean organic matter content is $3.7 \% \pm 1.0( \pm \mathrm{SD})$.

The macrobenthic assemblages at these sites were sampled from February 1993 to September 1995, fortnightly for the first 18 mo and monthly thereafter. On each sampling occasion 6 to 10 cores $(13.5 \mathrm{~cm}$ diameter) were taken to a depth of $20 \mathrm{~cm}$, washed over a $500 \mu \mathrm{m}$ mesh and the fauna retained, identified and enumerated.

The spatial and temporal dynamics of macrobenthic communities along the eutrophication gradient were analysed by non-metric MDS (Clarke \& Gorley 2001), following square root transformation (Clarke \& Warwick 2001) and by the PRC method, which is based on the redundancy analysis ordination technique, the constrained form of PCA, a full account of which can be found in Van den Brink \& Ter Braak (1999), Cuppen et al. (2000), Frampton et al. (2000a,b, 2001) and Van den Brink et al. (2000). The PRC method is a multivariate technique especially designed for data analysis from microcosm and mesocosm experiments. Due to its novelty, this method was mainly applied in aquatic ecotoxicology (Van den Brink \& Ter Braak 1999, Cuppen et al. 2000, Van den Brink et al. 2000), with only one incursion into soil ecology (Frampton et al. 2000a,b, 2001). However, this approach has potential for a wider application in community ecology and in the evaluation of ecosystem integrity. The method analyses differences in species composition between 'treatments' (sites, in the present study) at each time point, similar to other ordination techniques. However, one advantage of this method is that any temporal changes in the 'control' (the reference seagrass site, in the present study) are constrained in the plot to a horizontal line. Thus PRC creates a graphical display with time (sampling dates) as a horizontal line and the basic response pattern $\left(c_{d t}\right)$ of each site $d$ at each time $t$ in relation to control site on the vertical axis (by definition, the control site has always a $c_{d t}$ of zero for every time $-c_{0 t}$ ). When these coefficients are plotted for each time point, a principal response curve of the community is obtained for each site in comparison with the control site (Van den Brink \& Ter Braak 1999). This permits an easily-understood representation of the temporal changes in the assemblages at each site in relation to the reference control site.

An additional advantage of the PRC technique is that it allows for the detection of effects at the species level. Derived species weight $\left(b_{k}\right)$ is the factor by which the basic response pattern is multiplied to attain the fitted response of species $k$ (Van den Brink \& Ter Braak 1999). Species weights thus measure the affinity of a particular species to the community response pattern and can be used to estimate species relative abundance in each site compared to the control, using the expression $\exp \left(b_{k} c_{d t}\right)$. In practical terms, taxa with a positive species weight are expected to decrease in abundance relatively to the control in the highest treatment levels (i.e. the most eutrophic area in our case), whereas taxa with negative weights are expected to increase.

In PRC analysis, as described by Van den Brink \& Ter Braak (1999), the statistical model for the species abundance data is:

$$
Y_{d(j) t k}=Y_{0 t k}+b_{k} C_{d t}+\epsilon_{d(j) t k}
$$

where $Y_{d(j) t k}$ is the abundance of species $k$ in replicate $j$ of site $d$ at sampling date $t, Y_{0 t k}$ is the mean abundance of species $k$ on date $t$ at the control site $d_{0}, c_{d t}$ is a basic response pattern for every site $d$ and sampling date $t, b_{k}$ is the weight of each species with this basic response pattern and $\epsilon_{d(j) t k}$ is an error term with mean zero and variance $\sigma_{k}^{2}$. By definition, $c_{0 t}=0$ for every $t$. When the coefficients $C_{d t}$ are plotted against sampling date $t$, the resulting $\mathrm{PRC}$ diagram displays a curve for each treatment that can be interpreted as the principal response curve of the community (Van den Brink \& Ter Braak 1999). The species weight $b_{k}$ indicates how closely the response of each individual taxon matches the overall community response as displayed in the PRC diagram.

In previous studies that have used PRC analysis, an experimental 'control' treatment level was used as the reference treatment level $d=0$ (Van den Brink \& Ter Braak 1999). Here, however, and in common with Frampton et al. (2001), an obvious 'control' treatment does not exist among sampling times, and the least disturbed (most natural) site is viewed as the control. Although a reference level must be specified in the PRC analysis, the choice of reference does not limit the visual and quantitative treatment contrasts that can be made using a PRC diagram (Ter Braak \& Similaeur 1998).

In addition to providing a concise graphical summary of changes in community structure, PRC analysis allows an estimate of the variance in the data set that is explained by a treatment. A PRC diagram aims to maximise the amount of variance due to treatments; the higher the proportion of the variance displayed, the more closely will the fitted relative abundance of individual taxa inferred from the diagram match the observed relative abundance. The null hypothesis assumes that the PRC diagram does not capture the treatment variance (i.e. $c_{d t} \times b_{k}=0$ for all $t, d$ and $k$ ) and can be tested using a Monte Carlo permutation. A complete description of the method is provided in Van den Brink \& Ter Braak (1999). 
In the present study, treatments correspond to the different macrobenthic communities under different degrees of organic pollution stress. As reference (control) we considered the Zostera noltii meadows in 1993. PRC analysis was performed using the CANOCO software package, version 4 (Ter Braak \& Similaeur 1998). The significance of the PRC diagram was tested using a Monte Carlo permutation, by permuting the whole time series in the partial RDA from which the PRC analysis is obtained, using an F-type test statistic based on the eigenvalue of the first canonical axis (Van den Brink \& Ter Braak 1999).
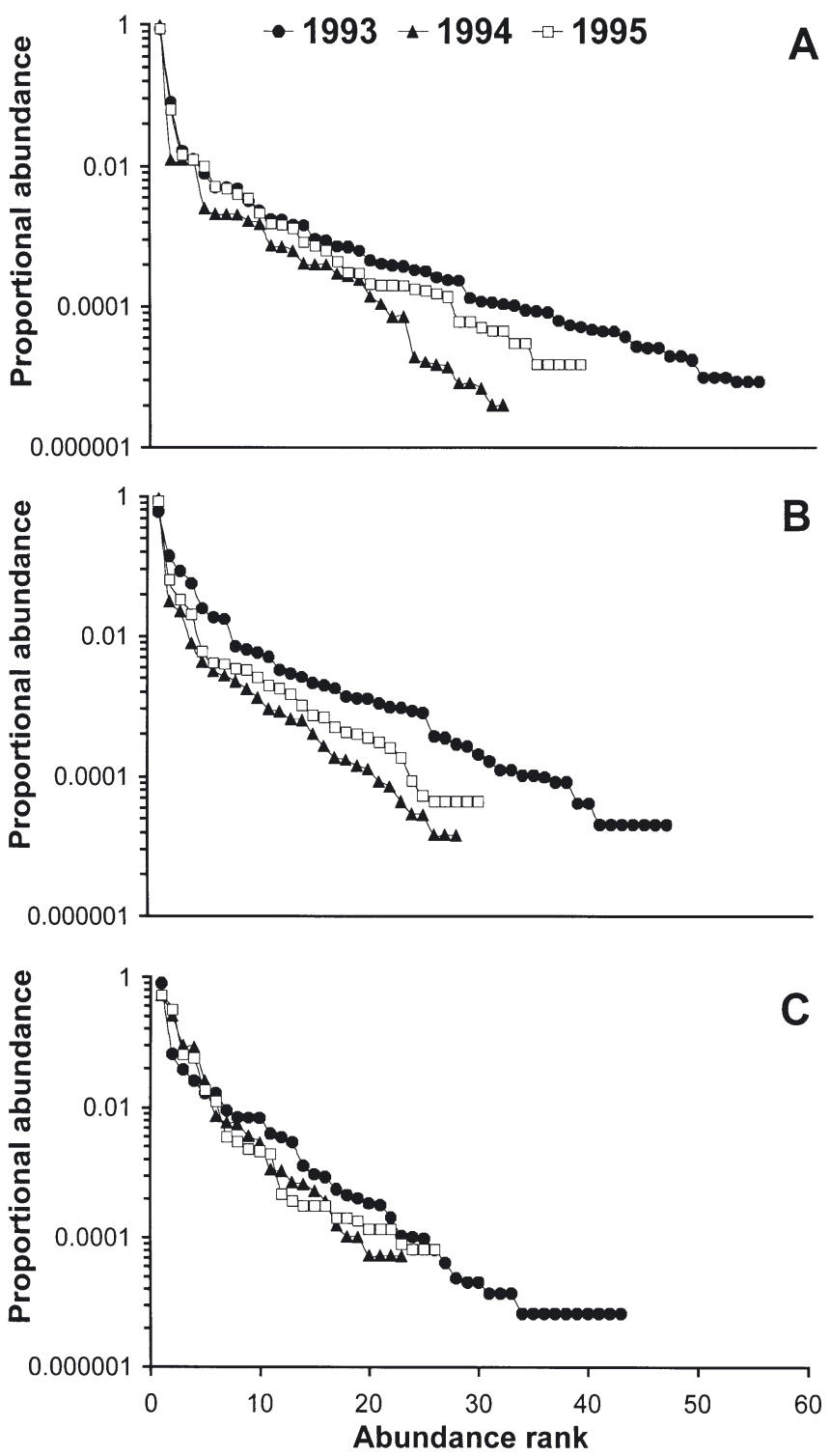

Fig. 2. Rank-abundance curves of the 3 macrobenthic communities. (A) Zostera noltii beds; (B) intermediate area; (C) most eutrophic/disturbed area

\section{RESULTS}

Throughout the period 1993 to 1995, the effects of eutrophication on benthic assemblages were studied in the Mondego estuary. Over these temporal and spatial scales, distinct changes in the structure of the macrobenthic communities were observed. The diversity of the macrobenthic communities in the 3 areas was assessed using rank-abundance curves (Fig. 2) (Molles 1999). These clearly show that the Zostera noltii beds always had a greater species richness (indicated by the number of ranks) than the most eutrophic area, with the intermediate zone having intermediate diversity. Evenness (indicated by the slope of the curve) increased from the $Z$. noltii beds to the most eutrophic area, contrary to expectation due to the dominance of Hydrobia ulvae in the $Z$. noltii beds (see also Cardoso et al. 2002), as can be seen by comparing the first and second ranks in the 3 areas. If $H$. ulvae is ignored, the evenness appears higher in the $Z$. noltii beds, consistent with expectations.

Over the past $10 \mathrm{yr}$, there was a decline in biodiversity over time (Cardoso et al. 2004) with 1993 showing higher species richness (Fig. 2). Nevertheless, some inter-annual variations in species richness can be seen and easily be understood in the scope of the intermediate disturbance hypothesis. At the end of the study period, species richness in the Zostera noltii beds (39 species) was similar to that observed in the most eutrophic area during the algal bloom (1993; 43 species), indicating a rapid deterioration of the seagrass habitat.

With regard to trophic groups, in the Zostera noltii meadows (Fig. 3A), detritivores and herbivores were clearly the dominant groups, taking advantage of the abundance of detritus resource provided by the decay of broken Zostera parts, and of grazing opportunities on epiphytes that cover Zostera leaves. Besides, Zostera leaves act as a trap for suspended sediments, and therefore for organic matter particles usable by detritivores (Valiela 1995). Omnivores and carnivores were always much less abundant. Therefore, despite seasonal variations, we observed the same stable pattern throughout the study period.

In the intermediate eutrophic area (Fig. 3B) the scenario appears totally distinct. Besides the fact that detritivores are dominant most of the time and carnivores always poorly represented, it is impossible to recognize any pattern through the study period, since trophic groups alternate very much in dominance (qualitative oscillations), which appear to correspond to a very unstable situation.

Finally, in the most eutrophic area (Fig. 3C), detritivores are by far the dominant group, followed by herbivores as a function of feeding opportunities 
provided by the macroalgae bloom (quantitative oscillations). As in the other 2 sampling stations, carnivores and omnivores are poorly represented.

The MDS plot shows that samples from the Zostera noltii beds were more different faunistically from those of the most eutrophic area, compared to those from the intermediate area (Fig. 4). Also, in the autumn of 1994 and winter of 1995, samples from the seagrass beds were closer in the ordination diagram to those from the most eutrophic area, consistent with the notion that the beds were in decline at the end of the study period. Samples from the intermediate and most eutrophic areas were the most widely dispersed in the ordination diagram (i.e. more variable in species composition), probably reflecting fluctuations in macroalgal biomass.

These trends were confirmed by ANOSIM. Zostera noltii beds were significantly different from the intermediate area and from the most eutrophic area $(R=0.387$, $\mathrm{p}=0.001 ; \mathrm{R}=0.273, \mathrm{p}=0.001$, respectively). Significant differences were observed for all sites between 1993 and $1994(\mathrm{R}=0.192$, $\mathrm{p}=0.02$ ) and also between 1993 and 1995 (R $=0.206, p=0.016)$. However, no significant differences were detected, for 1994 against $1995(\mathrm{R}=-0.03, \mathrm{p}=0.567)$.

The PRC analysis shows a clear spatial gradient related to eutrophication, in that the declining Zostera noltii beds (1994 to 1995 data set) are closer to the 1993 Z. noltii reference, followed by the intermediate area and finally the most eutrophic area (Fig. 5). Furthermore, the macrobenthic communities deviate further from the reference over time. In our analysis, sampling date accounted for $26.3 \%$ of the total variance within the data set, with $59.3 \%$ explained by the eutrophication gradient (the remaining time $\times$ site interaction). Of the total variance, $14.4 \%$ can be attributed to the differences between the sample replicates. Monte Carlo permutation tests revealed that the differences between the treatments (sites) and the reference were statistically significant $(\mathrm{p}<0.05)$, with the PRC diagram explaining $45.03 \%$ of the variance in treatment (site) effects.

The most affected taxa were the polychaete Chaetozone setosa and the oligochaete family Tubificidae, both with positive weights, indicating a reduced abundance, compared to that in the refer- ence site. In contrast, the taxon with the highest negative weight (i.e. which increased in abundance) was the polychaete Alkmaria romijni (Fig. 5), consistent with the premise that small deposit-feeding polychaetes increase in eutrophic conditions (Pearson \& Rosenberg 1978, Simboura et al. 1995).
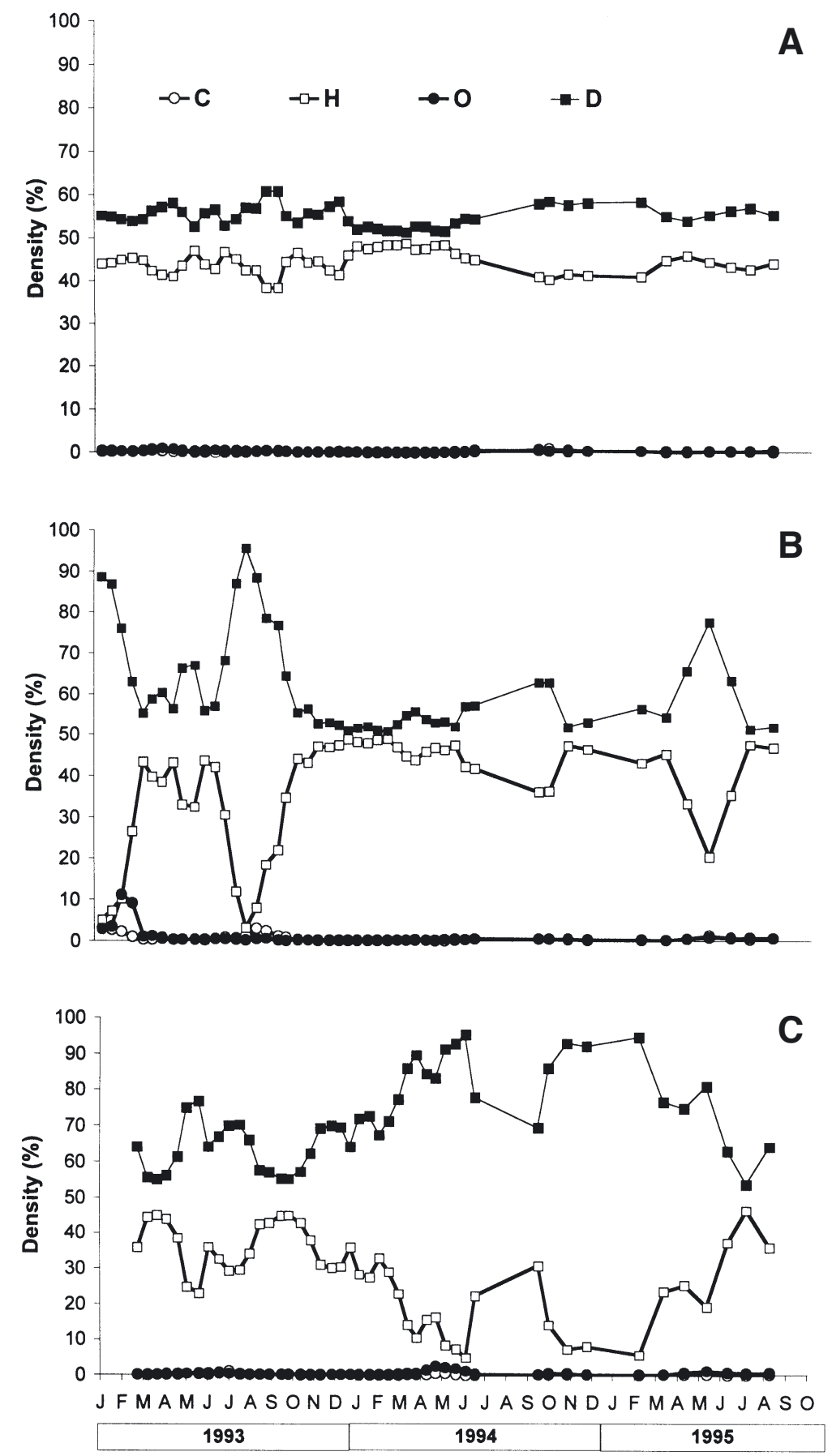

Fig. 3. Trophic structure of the 3 macrobenthic communities. (A) Zostera noltii beds, (B) intermediate area, (C) most eutrophic/disturbed area. Trophic groups: herbivores $(\mathrm{H})$, omnivores $(\mathrm{O})$, detritivores $(\mathrm{D})$, carnivores (C). Values are percentages of total individuals 
Stress: 0.12

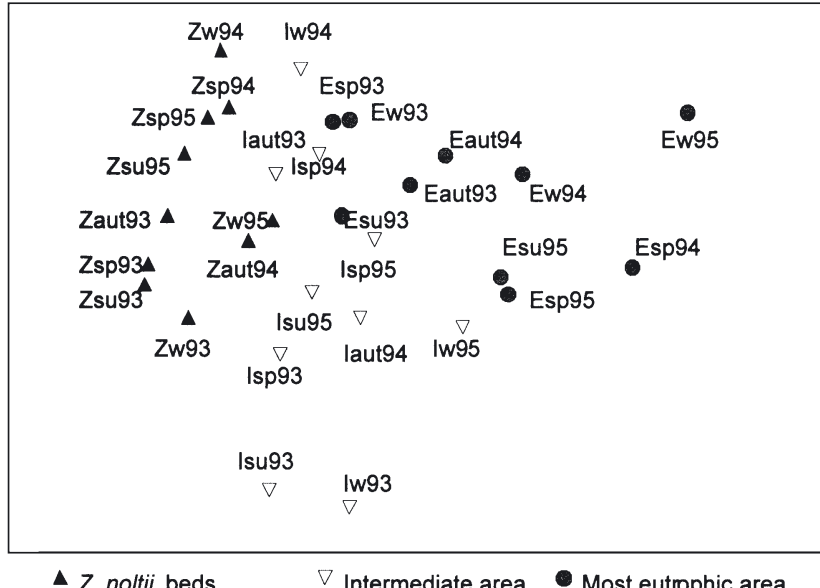

Fig. 4. Two-dimensional MDS ordination plot of macrobenthic communities. Z: Zostera noltii beds; I: intermediate area; E: most eutrophic/disturbed area; sp: spring; su: summer; aut: autumn; w: winter

\section{DISCUSSION}

Both the MDS and PRC analyses showed significant differences between the 3 sites, reflecting the levels of disturbance that they experience, as well as revealing a deterioration of in the seagrass beds over the study period. However, these trends are much clearer in the PRC diagram.

Mensurative or manipulative experiments in community ecology usually result in large data sets on treatment effects and how they change through time. Traditional ordination methods attempt to summarise

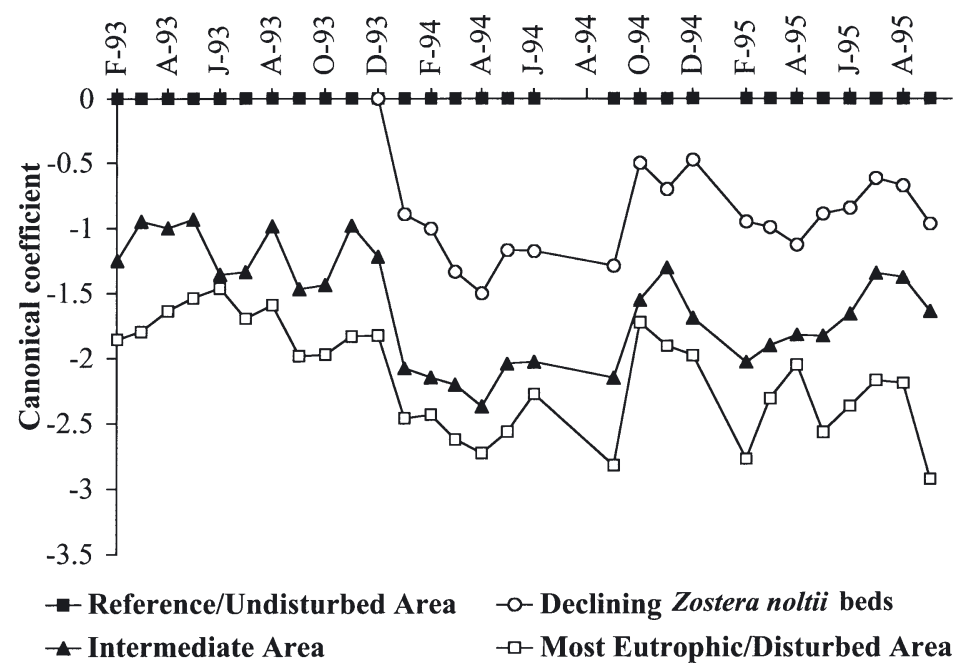

Fig. 5. Principal response curves (PRC) showing the response of macrobenthic communities to different degrees of organic pollution/disturbance, with species weights indicating the relative contribution of individuals species to the community response such change but diagrams can often be messy (Warwick \& Clarke 1991). The PRC approach compacts the complexity of time-dependent, community-level effects of stress into a simple and user-friendly diagram, facilitating both interpretation by the ecologist and the presentation of impacts to policy makers, managers and stakeholders. The elegance lies partly in the fact that PRC analysis represents the time trajectory for the control or reference site as a horizontal line, and partly because it permits the interpretation of effects at the level of the individual species. This is not achievable in an MDS analysis, because MDS works on a derived 'sample by sample' similarity matrix, which makes it difficult to show the individual taxa in the final ordination diagram.

PRC has advantages over other approaches used in community ecology or ecotoxicology, such as the BACI design, the use of similarity indices (e.g. Clarke \& Warwick 1994, Heimbach \& Ratte 1997, Sousa et al. 1997) or the use of biotic or diversity indices. These advantages lie not only with the final graphical display but also with the level of interpretation that the PRC allows. Although BACI and similar approaches may also have a user-friendly display of differences (dissimilarities) between treatments over time, allowing also

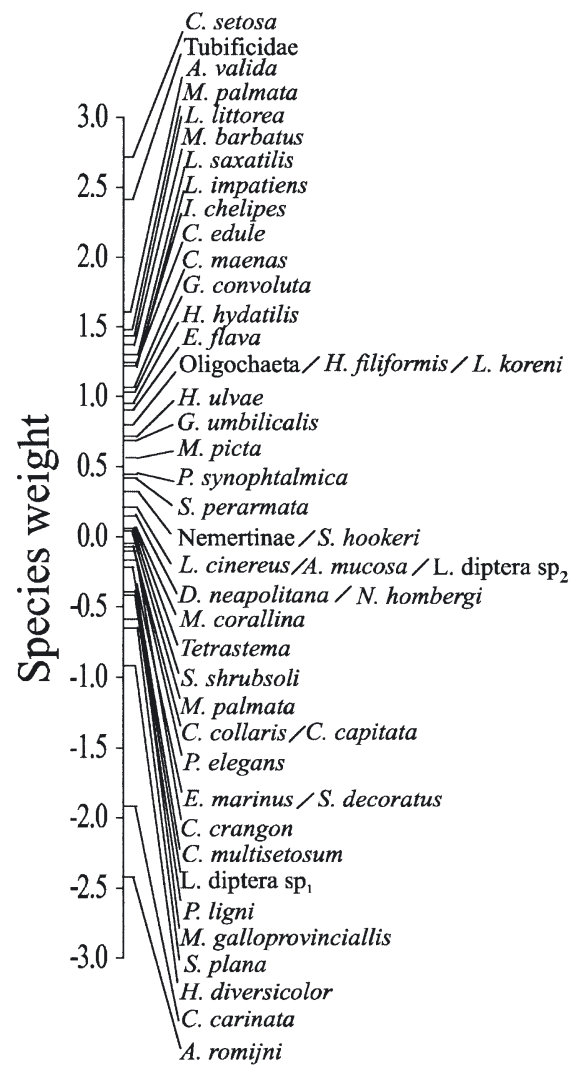



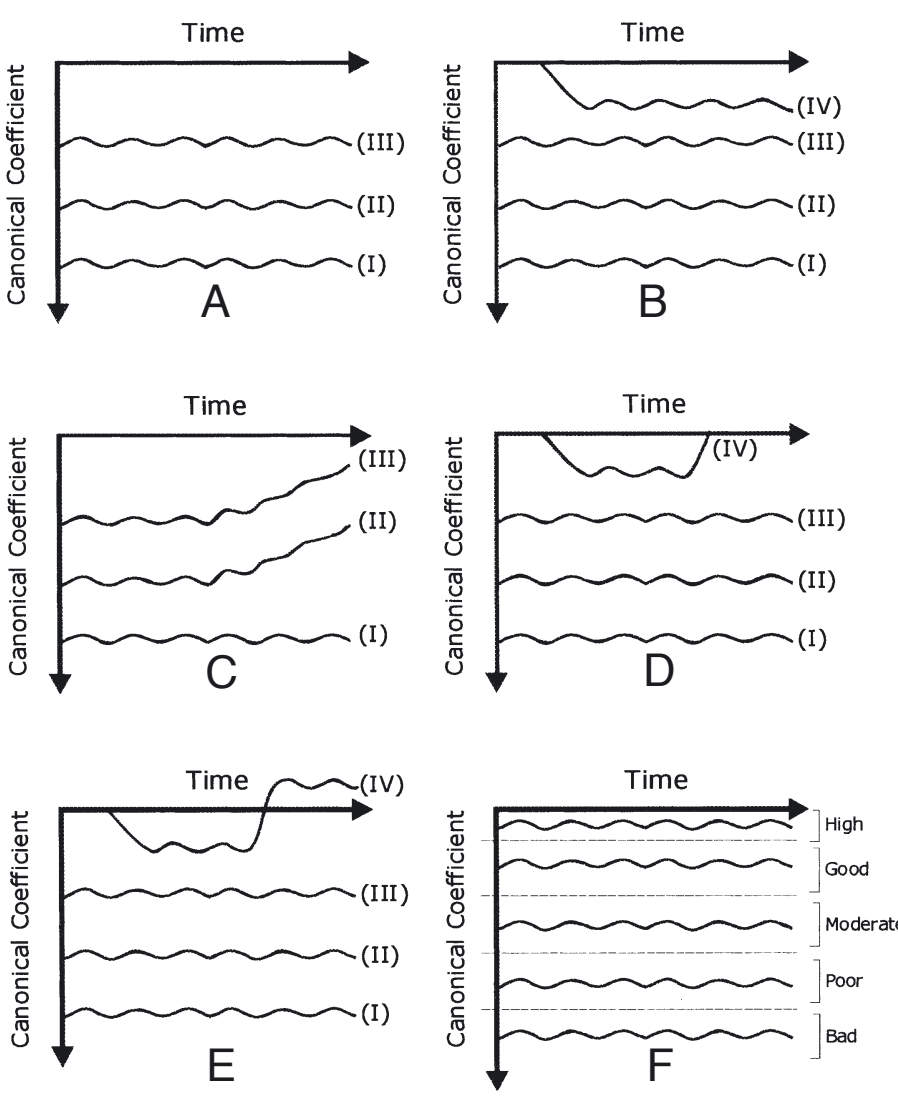

Fig. 6. Theoretical principal response curves (PRC) in response to different environmental scenarios. (A) typical gradient of disturbance, (B) decline of the reference area after disturbance, (C) recovery of environmental quality after management, (D) recovery of the reference area after management, (E) need to settle new reference values after management, (F) implementation of threshold values for qualitative environmental evaluation. (I), (II), (III) and (IV) are sites along a common disturbance gradient

the use of statistical tests to assess the significance of treatment effects, effective representation using indices is difficult to achieve. Moreover none of these methods allow an interpretation back to species level, as does PRC. This new technique is more likely to capture subtle changes that may only occur in a few species of the assemblage. This feature could also make the tool important for early detection of assemblage-level changes. However, one advantage of MDS or BACI over PRC is that it is possible to select a specific distance metric, such as the Bray-Curtis measure, while for PRC the user is presently restricted to Euclidean distances (Ter Braak \& Similaeur 1998).

Fig. 6 illustrates and summarises how PCR analysis can be applied to several common environmental scenarios independently of the number of sites analysed. For example, a very common disturbance gradient where site (I) is the closest to the disturbance point source (Fig. 6A); where changes occur in the originally defined reference area (Fig. 6B); to follow recovery of the environmental quality after management or mitigation measures (Fig 6C,D) that might lead to a better environmental quality than considered at first for the reference area (Fig. 6E); where the establishment of threshold values/levels are necessary for qualitative evaluation of ecosystem health (Fig. 6F), as will be required under the European Water Framework Directive (WFD 2000/60/EC).

In conclusion, we believe that PRC will provide a powerful tool for environmental quality assessment in the future and should be incorporated into monitoring and assessment programmes along with the existing range of univariate and multivariate tools presently used.

\section{LITERATURE CITED}

Borja A, Franco J, Perez V (2000) A marine biotic index to establish the ecological quality of soft bottom benthos within European estuarine and coastal environments. Mar Pollut Bul 40:1100-1114

Borja A, Muxika I, Franco J (2003)The application of a Marine Biotic Index to different impact sources affecting soft-bottom benthic communities along European coasts. Mar Pollut Bull 46(7):835-845

Cardoso PG, Lillebø AI, Pardal MA, Ferreira SM, Marques JC (2002) The effect of different primary producers on Hydrobia ulvae population dynamics: a case study in a temperate intertidal estuary. J Exp Mar Biol Ecol 277(2):173-195

Cardoso PG, Pardal MA, Lillebø AI, Ferreira SM, Raffaelli D, Marques JC (2004) Dynamic changes in seagrass assemblages under eutrophication and implications for recovery. J Exp Mar Biol Ecol (in press)

Clarke KR, Gorley RN (2001) Primer v5: User Manual/ Tutorial. Primer-E, Plymouth

Clarke KR, Warwick RM (1994) Similarity-based testing for community patter: the 2-way lay-out with no replication. Mar Biol 118:167-176

Clarke KR, Warwick RM (2001) Change in marine communities. An approach to statistical analysis and interpretation, 2nd edn. Primer-E, Plymouth

Cuppen JGM, Van den Brink PJ, Camps E, Uil KF, Brock TCM (2000) Impact of the fungicide carbendazim in freshwater microcosm. I. Water quality, breakdown of particulate organic matter and responses of macroinvertebrates. Aquatic Toxicol 48:233-250

Dolbeth M, Pardal MA, Lillebø AI, Azeiteiro U, Marques JC (2003) Short- and long-term effects of eutrophication on the secondary production of an intertidal macrobenthic community. Mar Biol 143(6):1229-1238

Flindt MR, Kamp-Nielsen L, Marques JC, Pardal MA and 5 others (1997) Description of the 3 shallow estuaries: Mondego River (Portugal), Roskilde Fjord (Denmark) and the lagoon of Venice (Italy). Ecol Model 102:17-31

Frampton G, Van den Brink PJ, Gould PJL (2000a) Effects of spring precipitation on a temperate arable collembolan community analysed using Principal Response Curves. Appl Soil Ecol 421:1-18

Frampton G, Van den Brink PJ, Gould PJL (2000b) Effects of spring drought and irrigation on farmland arthropods in southern Britain. J Appl Ecol 37:865-883

Frampton G, Van den Brink PJ, Wratten SD (2001) Diel activ- 
ity patterns in an arable collembolan community. Appl Soil Ecol 17:63-80

Gray JS (1979) Pollution induced changes in populations. Phil Trans R Soc Lond B 286:545-561

Heimbach F, Ratte HT (1997) Use of a similarity index to compare the species composition of aquatic communities in order to investigate ecosystem recovery. Abstract 7th Annual Meeting of SETAC-Europe, Amsterdam

Lillebø AI, Pardal MA, Marques JC (1999) Population structure, dynamics and production of Hydrobia ulvae (Pennant) (Mollusca: Prosobranchia) along an eutrophication gradient in the Mondego estuary (Portugal). Acta Oecol 20 (4):289-304

Marques JC, Maranhão P, Pardal MA (1993) Human impact assessment on the subtidal macrobenthic community structure in the Mondego estuary (Western Portugal). Estuar Coast Shelf Sci 37:403-419

Marques JC, Pardal MA, Nielsen SN, Jørgensen SE (1997) Analysis of the properties of exergy and biodiversity along an estuarine gradient of eutrophication. Ecol Model 102: 155-167

Martins I, Pardal MA, Lillebø AI, Flindt MR, Marques JC (2001) Hydrodynamics as a major factor controlling the occurrence of green macroalgal blooms in an eutrophic estuary: a case study on the influence of precipitation and river management. Estuar Coast Shelf Sci 52:165-177

Molles MC (1999) Ecology. Concepts and applications. McGraw-Hill, Dubuque, IA

Pardal MA, Marques JC, Metelo I, Lillebø AI, Flindt MR (2000) Impact of eutrophication on the life cycle, population dynamics and production of Ampithoe valida (Amphipoda) along an estuarine spatial gradient (Mondego estuary, Portugal). Mar Ecol Prog Ser 196:207-219

Pearson TH, Rosenberg R (1978) Macrobenthic succession in

Editorial responsibility: Otto Kinne (Editor),

Oldendorf/Luhe, Germany relation to organic enrichment and pollution of the marine environment. Oceanogr Mar Biol Annu Rev 16:229-311

Simboura N, Zenetos A (2002) Benthic indicators to use in ecological quality classification of Mediterranean soft bottom marine ecosystems, including a new biotic index. Mediterr Mar Sci 3/2:77-111

Simboura N, Zenetos A, Panayotidis P, Makra A (1995) Changes of benthic community structure along an environmental pollution gradient. Mar Pollut Bull 30(7): $470-474$

Sousa JP, Vingada JV, Barrocas H, Gama MM (1997) Effects of introduced exotic tree species on Collembola communities: the importance of management techniques. Pedobiologia 41:166-174

Ter Braak CJF, Similaeur P (1998) Canoco reference manual and user's guide to Canoco for Windows. Software for canonical community ordination (version 4). Microcomputer Power, Ithaca, New York

Valiela I (1995) Marine ecological processes, 2nd edn. Springer-Verlag, New York

Van den Brink PJ, Ter Braak CJF (1999) Principal Response Curves: analysis of time-dependent multivariate responses of biological community to stress. Environ Toxicol Chem 18(2):138-148

Van den Brink PJ, Hattink J, Bransen F, Van Donk E, Brock TCM (2000) Impact of the fungicide carbendazim in freshwater microcosm. II. Zooplankton, primary producers and final conclusions. Aquatic Toxicol 48:251-264

Warwick RM, Clarke KR (1991) A comparison of some methods for analysing changes in benthic community structure. J Mar Biol Assoc UK 71:225-244

Warwick RM, Clarke KR (1993) Comparing the severity of disturbance: a meta-analysis of marine macrobenthic community data. Mar Ecol Prog Ser 92:221-231

Submitted: March 19, 2003; Accepted: November 4, 2003

Proofs received from author(s): February 9, 2004 